\title{
INTERNACIONALIZAÇÃO DOS CAPITALISTAS E NACIONALISMO DOS TRABALHADORES
}

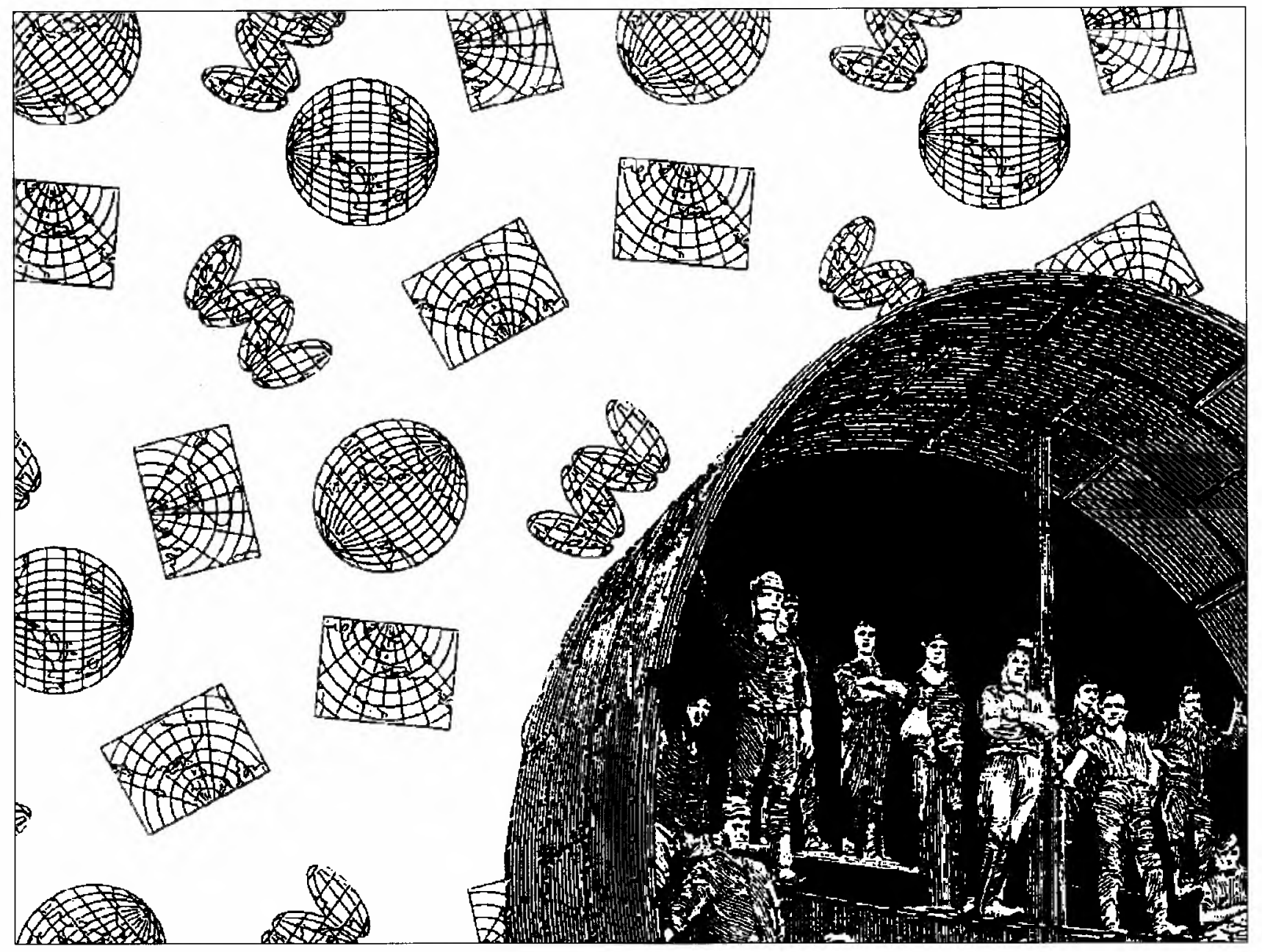

João Bernardo

Escritor, autor de vários livros, entre os quais Marx Crítico de Marx e Capital, Sindicatos, Gestores. Tem no prelo: Economia dos Conflitos Sociais e Crise da Economia Soviética.

* RESUMO: Partindo da consideração de que nos conflitos de classe a vantagem decisiva pertence àquela que está internacionalmente organizada, o autor pretende mostrar que na seqüência da Primeira Guerra Mundial tal vantagem cabia, na Europa, à classe trabalhadora. A crise desencadeada em 1929 permitiu aos capitalistas inverter a situação. A partir de então, à crescente transnacionalização do capital, a classe trabalhadora tem apenas oposto lutas ineficazes, porque limitadas por fronteiras nacionais.
* PALAVRAS-CHAVE: Sociedades multinacionais, classe trabalhadora, internacionalismo, guerras mundiais.

* ABSTRACT: Considering that in the class conflicts the advantage belongs to the internationally organized one, the author states that, with World War I, such an advantage was, in Europe, on the side of the working class. The 1929 economic crisis allowed the capitalists to change the situation. Since then, when opposing the evergrowing capital transnationalization, the working class has been on the losing side, as it is limited by national frontiers.

* KEY WORDS: Multinational companies, working class, internationalism, world wars. 
$\mathrm{U}$ $\mathrm{m}$ dos aspectos que mais decisivamente caracteriza a situação econômica e social das últimas décadas consiste na conjugação entre a internacionalização do capital e a fragmentação nacional da classe trabalhadora.

Quanto à internacionalização do capital, escusado será chamar a atenção para a importância das sociedades multinacionais. A ordem de grandeza dos montantes e dos fluxos dos investimentos externos diretos é por todos bem conhecida e ninguém ignora, também, que, num grande número dos países onde as multinacionais implantam as filiais, elas atingem uma dimensão tal que freqüentemente retira qualquer eficácia às tentativas de organização nacional da economia. É, todavia, mais raro considerar que o mesmo sucede relativamente aos principais países industriais, onde as grandes sociedades estabelecem as suas sedes, e entre os quais se cruza a maior parte dos investimentos diretos. Um economista calculou que, nos meados da década de 1970, do total mundial de transferências externas de bens e serviços (financeiros e de fatores, por exemplo, royalties) metade ocorria no interior de sociedades multinacionais, entre sedes e filiais ${ }^{1}$. A tendência é para o aumento dessa proporção e, certamente, ela é hoje mais considerável ainda. Aquilo que, sob o ponto de vista nacional, tanto para os países considerados dominantes como para os chamados de periferia, constitui comércio externo são transferências internas na perspectiva das sociedades multinacionais. $E$, assim, não é apenas dos pequenos países, de economias fracas, que a rede dos investimentos diretos oriundos do estrangeiro retira qualquer possibilidade de soberania econômica, mas, também, os órgãos políticos nos países mais desenvolvidos são esvaziados do poder à medida que as grandes sociedades multinacionais passam a controlar, no seu interior, o que antes decorria das relações entre Estados. Não têm, por isso, nenhum significado rigoroso as comparações tão freqüentemente estabelecidas entre a dimensão das multinacionais e a das economias nacionais. Não se podem contabilizar duas vezes os mesmos valores e muito do que se apresenta como decorrente das economias de cada país processa-se no interior das redes multinacionais. Aliás, é esse substrato, a permitir as transferências monetárias maciças e súbitas, que deixou sem eficácia o controle estritamente nacional do dinheiro e apressou o colapso do sistema acordado em Bretton Woods.
As sociedades multinacionais não se limitam, em suma, a prevalecer sobre as economias nacionais, quer sob o ponto de vista dos países onde estão estabelecidas as sedes, quer sob o daqueles onde implantam as filiais - tanto mais que essas categorias se sobrepõem nos países desenvolvidos. É a própria noção de soberania econômica a diluir-se e só por um artifício estatístico pode continuar hoje a ser atribuído um perfil nacional a movimentos que se processam no interior de cada uma das grandes sociedades multinacionais.

Com essa transnacionalização do capital, contrasta-se o estrito nacionalismo em que a classe trabalhadora se encontra repartida. À primeira vista, poderia parecer apenas um mero corolário da fragmentação da força de trabalho no interior de qualquer unidade econômica, seja um país ou uma empresa. Um dos principais objetivos de uma boa gestão consiste em dividir os trabalhadores por equipes e categorias, não sobreponíveis e além disso mutáveis, e em impedi-los de estabelecerem, por iniciativa própria, relações diretas no interior das unidades em que laborem. Dessa forma, reproduz-se o afastamento dos trabalhadores relativamente ao controle dos processos econômicos e assegura-se, portanto, a extorsão da mais-valia. A transnacionalização do capital não se limita, porém, a desenvolver esse tipo de individualização da classe trabalhadora. Tem-se, nas últimas décadas, reforçado um segundo nível de fragmentação, o das fronteiras nacionais, fazendo com que os trabalhadores, ao mesmo tempo que são dispersos individualmente enquanto classe, sejam unificados enquanto membros de nações e assim opostos uns aos outros em grandes grupos hostis. Trata-se de uma situação especialmente paradoxal, já que a transnacionalização do capital retirou dos países qualquer sentido econômico próprio, de maneira que os aparelhos tradicionais de governo se voltam hoje exclusivamente para a contenção e a dispersão da força de trabalho. O nacionalismo tornou-se real apenas para a classe trabalhadora. Os capitalistas estão inteiramente internacionalizados.

A importância que os capitalistas atribuem à divisão nacional dos trabalhadores pode avaliar-se pelo que tem sucedido com os sindicatos. Em termos sincrônicos, parece indiferente que a organização da força de trabalho se deva aos departamentos de empresa criados com este fim ou esteja a cargo dos sindicatos. Diacronicamente, porém, os primeiros nasceram por iniciativa do patronato, enquanto os atuais aparelhos sindicais resul- 
taram de um processo histórico de burocratização de organismos criados nas lutas trabalhadoras. Certamente por isso, grande parte dos capitalistas parece ter um receio, a meu ver exagerado, de que os sindicatos burocráticos possam regressar, pelo menos em parte, às finalidades de origem. As burocracias sindicais chegaram já ao estágio terminal da evolução capitalista, convertendo o seu controle sobre a força de trabalho em efetiva propriedade do capital ${ }^{2}$, mas, apesar disso, o patronato tradicional tem impedido que a participação sindical na propriedade se beneficie de qualquer processo de internacionalização. É este o único campo da gestão a manter-se confinado pelas fronteiras nacionais. $\mathrm{E}$ quando sabemos que, em 1985, dos $90 \mathrm{mi}-$ lhões de operários industriais nos países da OCDE, 30 milhões eram assalariados em firmas multinacionais ${ }^{3}$, podemos facilmente entender que, limitados no âmbito de cada país, os sindicatos facilmente sejam ultrapassados pelos departamentos de empresa especializados na organização da força de trabalho. É um dos fatores, embora não o único, a explicar o declínio dos aparelhos sindicais.

No final da década de 1970, parecia que a situação se anunciava de maneira diferente e que os sindicatos acompanhariam a internacionalização dos restantes organismos de gestão do capital. Em 1975, quando o grupo, de origem francesa, BSN-Gervais-Danone tomou o controle da firma vidreira belga Glaverbel, esta assinou um protocolo sobre questões de emprego com representantes de catorze centrais sindicais belgas, holandesas, francesas, alemãs e austríacas, prometendo uma distribuição equitativa dos postos de trabalho entre esses países e constituindo um comitê internacional, integrado pelo patronato e por representantes sindicais, que deveria reunir-se duas vezes por ano e ser obrigatoriamente consultado antes de tomadas decisões que pudessem ter repercussões significativas sobre o emprego. $O$ escândalo nos meios tradicionais foi grande e a direção do grupo principal foi convocada pela confederação patronal francesa para explicar as razões de um acordo sem precedentes. Posteriormente, representantes da International Metalworkers Federation reuniram-se na Suécia com membros da direção da SKF e com dirigentes sindicais desse país, obtendo da firma a promessa de que não favoreceria o emprego em certos países em detrimento de outros. E em 1977, reuniram-se elementos da direção da Volvo e dirigentes da International Metalworkers Federation e de sindicatos bel- gas, holandeses e suecos para discutir o efeito sobre o emprego dos planos de investimento e de produção da empresa ${ }^{4}$. Estava assim traçado o caminho que levou o então comissário para os Assuntos Sociais da Comunidade Econômica Européia (CEE), o socialista holandês Henk Vredeling, a apresentar em 1980 uma proposta de diretiva segundo a qual as companhias multinacionais deveriam informar e consultar os sindicatos nas questões suscetíveis de afetar o emprego.

As direções das multinacionais, principalmente das sediadas nos Estados Unidos, mas também das de origem européia e japonesa, lançaram então o que The Economist apelidou de "a mais dispendiosa campanha de pressões na história do Parlamento [Europeu]", na qual "gastaram uma pequena fortuna". Cedendo a essas influências, o Parlamento Europeu, em outubro de 1982, aprovou a proposta com alterações tantas e tais que a tornariam inteiramente ineficaz. Do âmbito da diretiva, estariam excluídas as firmas que tivessem na área da CEE menos de mil assalariados e as filiais com menos de cem; aumentar-se-iam os poderes discricionários do patronato para declarar a confidencialidade de qualquer informação; ficariam reduzidos o volume das informações a se fornecerem aos sindicatos e o período de consulta; e os sindicatos seriam proibidos de ultrapassar a direção das filiais e recorrer diretamente à direção da empresasede. A Comissão procurou então chegar a um meio-termo, aceitando em boa parte as alterações introduzidas pelo Parlamento, mas tentando limitá-las, nomeadamente, concedendo aos sindicatos a possibilidade de recorrerem, embora apenas por escrito, à direção das empresas-sede contra decisões tomadas pelas filiais; e restringindo os poderes discricionários que haviam sido atribuídos às direções das multinacionais quanto à declaração do caráter confidencial das informações. Com essas remodelações, a proposta de diretiva não previa que as direções das firmas multinacionais fornecessem anualmente aos sindicatos mais do que informações comparáveis às que davam aos acionistas.Apesar disto, as multinacionais não aceitaram o compromisso e a sua oposição continuou inabalável, condenando, afinal, a proposta a ser vetada em 1984 num Conselho de Ministros da $\mathrm{CEE}^{5}$.

Os conflitos e os jogos de força entre as direções das grandes empresas e as burocracias sindicais travam-se, porém, no interior de uma mesma classe capitalista e só em aspectos acessórios podem refletir a iniciativa dos
2. Pretendi analisar o processo dessa conversão no meu livro Capital, Sindicatos, Gestores. Sã̃o Paulo, Vértice, 1987, pp.11-66.

3. THE ECONOMIST, $24 \mathrm{de}$ janeiro de 1987, p.60.

4. Sobre estes três casos ver The Economist, 15 de outubro de 1977, pp.89-93.

5. Sobre a Proposta Vredeling e o seu destino, ver The Economist de 16 de outubro de 1982, p.73; 20 de novembro de 1982, p.34; 25 de junho de 1983, p.60; 19 de novembro de 1983, p.68 e 13 de outubro de 1984 pp.75-6. Ver também Business Week de 25 de outubro de 1982, p.42 e de 01 de novembro de 1982, p.32. 
trabalhadores. Por isto, a fragmentação nacionalista a que parece condenar-se a classe trabalhadora, em contraste com a internacionalização do capital, talvez seja mais cabalmente demonstrada pelo que está hoje a ocorrer na Europa de Leste e na União Soviética. Nas três repúblicas bálticas, os trabalhadores autóctones têm ativamente apoiado a tecnocracia e as burocracias também autóctones no movimento de independência. Contra eles, e a coberto de referências ao internacionalismo, os trabalhadores de origem russa têm procurado travar o processo e manter a Lituânia, a Letônia e a Estônia integradas na União. A classe trabalhadora aparece assim dividida, defendendo os russos um nacionalismo expansionista e apoiando os bálticos os respectivos movimentos de independência. Na periferia meridional da União, o recente conflito entre o Azerbaijão e a Armênia, que se deflagrou primeiro ao nível das burocracias estatais, rapidamente se alastrou a toda a população, e passaram a ser os trabalhadores de cada um dos lados a impor ao conflito o ritmo $\mathrm{e}$ as próprias formas de organização. $\mathrm{Na}$ Romênia, foi a solidariedade manifestada pelos trabalhadores de origem romena para com os de origem húngara, vítimas de uma especial perseguição desencadeada pelo regime de Ceausescu, que deu origem ao levantamento popular e pôs termo à ditadura. E, no entanto, escassas semanas após essa triunfante demonstração de unidade, sangrentas rivalidades voltaram a opor trabalhadores de ambas as etnias. $\mathrm{Na}$ Tchecoslováquia, a população fala já abertamente da cisão das duas partes constitutivas do país. E na Iugoslávia, as rivalidades nacionais chegaram a um ponto crítico, transformando a Federação numa ficção e erguendo os trabalhadores sérvios contra os albaneses de Kosovo; levando os trabalhadores croatas e eslovenos a se defenderem, contra o expansionismo da Sérvia, o "independentismo" das suas repúblicas; fazendo com que os trabalhadores sérvios, em nome da unidade da república federada, apóiem, na realidade, o expansionismo autoritarista dos dirigentes do partido comunista sérvio. Em suma, um ativíssimo movimento popular, em que a classe trabalhadora tomou o papel determinante e que levou ao colapso sistemas políticos e econômicos vigentes durante décadas, tem- se processado num quadro de reforço do nacionalismo e até dos subnacionalismos.

Enquanto tudo isso sucede, as maiores empresas multinacionais encabeçam o movimento de criação de novos quadros políticos, econômicos e financeiros destinados a inserir decisivamente e sem apelo as economias do Leste Europeu e da União Soviética na rede mundial dos investimentos diretos. Esse processo de internacionalização do capital apenas aparentemente é contraditório com o nacionalismo expresso pela classe trabalhadora nesses países. Quanto mais se acentuarem as rivalidades nacionais e se esboroarem fronteiras até há pouco tidas por definitivamente estabelecidas, tanto mais facilmente as multinacionais penetrarão esse espaço. A multiplicação de centros de decisão governamentais, reciprocamente hostis, enfraquece-os a todos e a cada um deles, anulando as capacidades de decisão dos órgãos tradicionais de Estado, que se encontram já comprometidas pelo reforço das maiores empresas enquanto aparelhos de poder. Do mesmo modo que há três décadas, a descolonização africana, operando-se no quadro de uma pluralidade de fronteiras e não nos moldes do sonhado panafricanismo, facilitou a atividade às multinacionais, também agora na Europa de Leste e na União Soviética ser-lhes-á muito mais fácil subjugar espaços econômicos internamente repartidos. A integração e unificação a nível do capital são estimuladas pela fragmentação ao nível da classe trabalhadora.

Nem sempre, porém, os trabalhadores se mostraram incapazes de opor ao desenvolvimento do capitalismo uma resistência internacional. Assim como não esteve sempre garantida a coesão internacional das classes dominantes.

A Guerra Mundial de 1914-1918 fraturou as classes dominantes, não segundo clivagens ideológicas e de sistemas de organização político-econômicos, mas rigorosamente consoante as fronteiras nacionais. Entre os camponeses, o operariado industrial e os pequenos empregados enviados para morrer e matar nas frentes de batalha, desenvolveu-se, porém, uma situação em tudo oposta. De abril até setembro de 1917, mas sobretudo em maio e na primeira metade de junho, uma onda de motins percorreu a maior parte do exército francês, exigindo uma rápida paz negociada, recusando obedecer às ordens, realizando manifestações e desertando em grandes números. Os responsáveis políticos e militares compreenderam, desde o início, que a repressão seria insuficiente: os altos comandos foram mudados, definiu-se uma nova estratégia que diminuísse a perda de vidas. Mas mais do que essas cedências, o que permitiu aos Aliados não soçobrarem foi a entrada dos Estados Unidos no conflito e a chegada de 


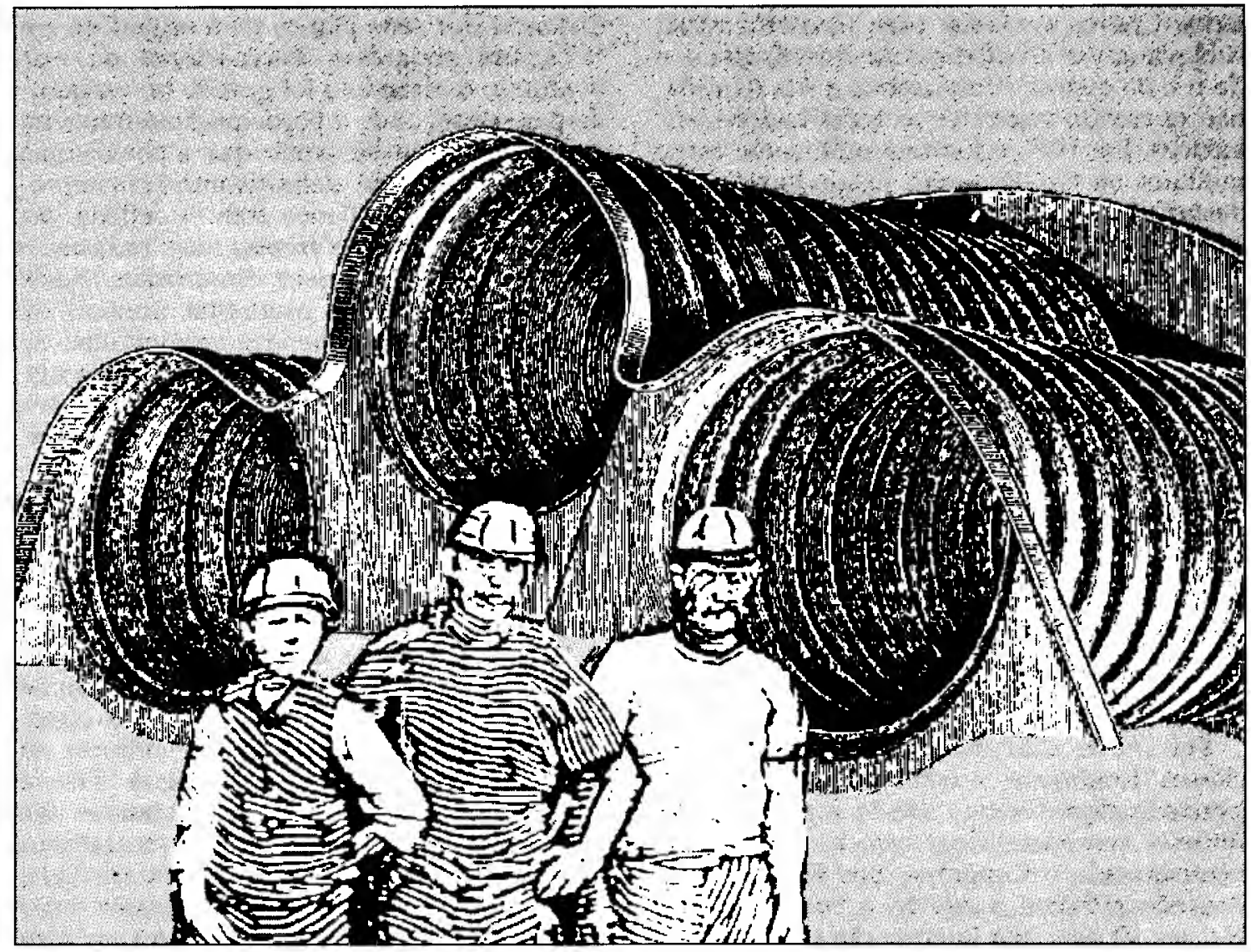

tropas frescas de além-Atlântico, sem terem ainda experimentado os horrores da guerra nem tido tempo para se solidarizar com os amotinados. As revoltas dos soldados, por um lado, refletiam e, por outro, incentivavam as greves dos civis. De 1916 a 1917, o número de movimentos grevistas na França subiu $600 \%$ e a quantidade de trabalhadores envolvidos aumentou mais de $3.000 \%$, atingindo quase os trezentos mil. Mas o decisivo é que um tão amplo movimento não teria podido manifestar-se se não se tivessem tecido laços de fraternidade entre trincheiras inimigas. Ao longo de 1916, foram-se tornando mais freqüentes, nos intervalos das chacinas, os contatos entre soldados franceses e alemães, enterrados na lama por vezes a escassas dezenas de metros de distância. Em 1916, o número de dias de trabalho perdidos por greve na Alemanha aumentara $500 \%$ em relação ao ano anterior. Em 1917, atingia os dois milhões, um acréscimo de $700 \%$ em relação a 1916, tendo guarnições de bases navais apoiado o movimento; e as paralisações foram mais amplas ainda em 1918. Na Grã-Bretanha,as importantes greves de 1916 e 1917 marcaram o início do movimento dos Shop Stewards e em
1918 eclodiram motins entre tropas britânicas estacionadas na França. Na Itália, em 1917, as revoltas coletivas de soldados foram menos numerosas do que na França, mas a deserção foi muito mais maciça, a tal ponto que a polícia não ousava prender os que abandonavam as unidades e pura e simplesmente regressavam a casa. E no exército russo, a insubordinação dos soldados atingiu um ponto tal que, em julho de 1917, a linha de frente se desagregou por completo.

Os anos de 1916 e 1917 assinalam o início, na Europa, entre os camponeses e os trabalhadores urbanos, de um movimento de sublevação que não se circunscreveu a cada país e foi capaz de uma ampla fraternização por cima das fronteiras. A dimensão alcançada pela Revolução Russa, de outubro de 1917, e as suas repercussões históricas não nos devem fazer esquecer de que se tratou originariamente de um desses movimentos. E quando, desde o início da guerra civil, os governos aliados intervieram militarmente na Rússia ao lado dos contra-revolucionários, foram ainda os motins dos soldados que os levaram a suspenderem a participação ou a reduzirem o empenho com o que faziam. As forças dos Es- 
tados Unidos enviadas para território russo sublevaram-se ao saberem da derrota alemã e do fim da guerra, e impuseram a sua retirada, não querendo combater os trabalhadores soviéticos. Em 1919, eclodiram motins em bases militares na Grã-Bretanha, exigindo a rápida desmobilização, o que impediu os governantes de enviarem soldados do contingente para a guerra civil russa. E também em 1919, as tropas estrangeiras tiveram de evacuar o sul da Ucrânia, em virtude da revolta da armada francesa. A Insurreição de março de 1921, na base naval de Kronshtadt, aspirando desesperadamente a um regresso aos princípios originários da revolução russa, foi talvez o último episódio desse qüinqüênio de motins e insurreições militares. Foram anos decisivos, durante os quais os trabalhadores urbanos $e$ os camponeses se mostraram capazes de estabelecer na Europa uma fraternidade alémfronteiras e de obrigar os governos e os comandos militares dos vários países a inflectirem as suas estratégias.

Foi muito diferente a situação entre as classes dominantes e nem sequer a paz lhes trouxe qualquer efetiva coesão supranacional. Entre os vencedores, logo uma fratura se verificou quando o Congresso dos Estados Unidos não ratificou a adesão à Sociedade das Nações. O país cuja intervenção tinha decidido na guerra o lado da vitória e que se afirmava como a potência econômica em ascensão manteve-se assim afastado do principal organismo de cooperação internacional. Nessas circunstâncias, a Sociedade das Nações estava condenada ao insucesso e os esforços diplomáticos de Briand e de Stresemann, de um e outro lado do Reno, não conseguiram reorientar as classes dominantes para um eixo de solidariedade européia. É fácil, evidentemente, censurar o nacionalismo alemão cada vez mais extremo, que acabaria por levar ao regime hitleriano. Suspeitavelmente fácil, se esquecermos do lado das classes dominantes francesas, o nacionalismo não menos histérico e vingativo. Debussy, renegando a influência da música alemã que tão determinante fora nas suas inovações de linguagem, assina no final da vida Debussy musicien français. Jean Wiener, que animava em Paris a difusão da música de vanguarda, vê-se obrigado a apresentar o Pierrot Lunaire de Schoenberg cantado em francês, porque passara a ser proibido por lei o uso da língua alemã em espetáculos públicos. Até Breton, que se imaginava, porém, tão radicalmente antiburguês, ataca em termos grosseiramente patrioteiros o cosmopolita romeno Tristan Tzara, quando este se distancia dos seus planos para organizar, em 1922, um congresso internacional de arte moderna; o escândalo foi grande na vanguarda parisiense, onde a participação estrangeira era numerosa, a tal ponto que a convocação do congresso ficou definitivamente comprometida. O meio artístico francês refletia, assim, mesmo nas suas franjas mais radicais, $o$ nacionalismo das classes dominantes. Ravel era dos poucos, no panorama musical de Paris, a manter uma lucidez cosmopolita, do mesmo modo que Keynes, entre os economistas e funcionários governamentais, se contava entre a minoria que alertara para As Consequiências Econômicas da Paz. Ao procurar extorquir da Alemanha reparações de guerra demasiado pesadas, os vencedores revelavam-se mais presos a uma política mercantilista de espoliação do que a uma estratégia capitalista de desenvolvimento.

Essa imaturidade das classes dominantes para assumirem plenamente as exigências do crescimento econômico levou então a classe trabalhadora a imaginar ter-se entrado na crise final do sistema. A Primeira Guerra Mundial e os anos que imediatamente lhe sucederam foram tanto mais ameaçadores para o capitalismo quanto a solidariedade, que se desenvolvia internacionalmente entre os trabalhadores europeus, contrastava com as dificuldades de coesão supranacional das classes dominantes. A crise de 1929 parece ter proporcionado uma viragem decisiva.

Na década de 1930, a denúncia keynesiana das rivalidades nacionais enfraquecedoras passou a encontrar uma aceitação crescente entre os dirigentes políticos e econômicos. A guerra mundial, que todos sabiam próxima, anunciava-se com um perfil muito diferente do da anterior. Nos países europeus ocupados pela Alemanha nazista, a resistência fundiu aqueles que eram antialemães por serem nacionalistas, por vezes mesmo de extrema-direita, com aqueles que, por serem antifascistas, se convertiam em antialemães. Essa deslocação do antifascismo popular para um antigermanismo $e$, conseqüentemente, para a apologia patriótica do país invadido, reforçou os quadros nacionalistas entre as populações trabalhadoras, de um e outro lado. Na Europa Ocidental, toda a política interna do pósguerra, até hoje, tem sido marcada por essa convergência entre uma direita que, sendo nacionalista, se tornou resistente e uma esquerda que não conseguiu ser resistente sem se converter ao nacionalismo. $\mathrm{O}$ processo não teve consequiências menos decisivas na União Soviética, onde a invasão nazista reforçou as 
credenciais nacionalistas do regime staliniano e permitiu-lhe coroar um longo processo de conversão de uma revolução internacional num Estado Nacional. Esse mesmo nacionalismo presidiu à resistência popular na Europa de Leste, o que contribui possivelmente para explicar porque pôde Stalin frustrar as tentativas de federação balcânica ensaiadas por Tito.

Mas enquanto na classe trabalhadora a Segunda Guerra Mundial se processava em termos exclusivamente nacionais, entre os capitalistas as clivagens haviam-se tornado supranacionais, dividindo-os ou unindo-os consoante os modelos de organização econômica e política propostos. Nos Estados Unidos, durante a guerra, Pierre Monteux dirige, em memória de um familiar muito próximo caído em batalha, a Morte e Transfiguração do alemão Richard Strauss.

Outra vez a música! Que tem ela a ver com tudo isso? Tem, e muito. A música, a mais abstrata das artes, e o dinheiro, o mais abstrato dos instrumentos econômicos, são os primeiros e os mais sensíveis dos indicadores capazes de dar conta das transformações sociais.

Os partidos políticos colaboracionistas que surgiram nos países ocupados pelos nazistas não se deveram apenas ao oportunismo de uns quantos, dispostos a tudo para cair nas boas graças do invasor. Vinham na continuidade de um movimento com autênticas raízes locais, a tal ponto que das 910.000 pessoas que até ao final de 1944 haviam integrado as fileiras das Waffen S.S. - o corpo de elite não só político-militar mas também "racial", destinado a servir de gérmen dos sonhados arianos -, apenas $45 \%$ eram originárias do Reich, sendo mesmo $17 \%$ consideradas estrangeiras ao conjunto da "raça germânica"'. Enquanto na guerra de 1914-1918, era contra os trabalhadores em greve, contra os internacionalistas, contra os soldados amotinados, contra todos os que defendiam a urgência de uma paz negociada que se voltavam as instituições repressivas do governo britânico, em 1939 Sir Oswald Mosley e outros fascistas eram internados, não por se pronunciarem contra as guerras, mas por nestas defenderem o lado contrário. $\mathrm{E}$ se o grande poeta norte-americano Ezra Pound fazia na Rádio de Roma, de 1941 a 1943, centenas de palestras defendendo a ideologia e a prática fascistas, um célebre físico italiano antifascista, Enrico Fermi, desde 1939 refugiado nos Estados Unidos, escrevia, junto com dois outros físicos de origem húngara e de formação germânica, também eles fugidos do nazismo, a notória carta que outro alemão emigrado do seu país, Einstein, assinou, e que decidiria o presidente norte-americano a organizar o que ficou conhecido como o Manhattan Project, a exploração para fins bélicos do processo de fissão nuclear. Hiroshima e Nagasaki puderam experimentar o resultado dessa colaboração ideológica e supranacional conduzida ao nível das classes dominantes, enquanto a população trabalhadora se trucidava reciprocamente, repartida por fronteiras nacionais.

Nas suas memórias, aquele que depois de ter sido o arquiteto preferido de Hitler e o mais próximo dos seus colaboradores pessoais, Albert Speer, tornou-se, a partir do início de 1942, o ministro responsável por supervisionar o esforço de guerra da indústria alemã, finge um espanto ingênuo perante o fato de a aviação britânica e norte-americana não ter prosseguido com suficiente sistematicidade o bombardeamento das mais decisivas instalações industriais, o que, em escassos meses, teria frustrado a continuação da produção militar nazista e antecipado o final do conflito. $\mathrm{O}$ bombardeamento aéreo das grandes fábricas de rolamentos de esferas, por exemplo, iniciado em agosto de 1943, foi, desde o início, conduzido de maneira dispersa e não se renovou com suficiente sistematicidade; retomado em fevereiro do ano seguinte, foi de novo suspenso em abril. "Pela sua falta de persistência", escreve Speer, "os Aliados deixavam uma vez mais escapar-lhes o êxito. Se tivessem prosseguido com a mesma tenacidade os bombardeamentos de março e de abril, depressa teríamos chegado ao limite dos nossos recursos". Ninguém é mais apto do que ele para afirmar que se todas as fábricas de rolamentos de esferas tivessem sido alvo de ataques simultâneos, sistematicamente repetidos, em quatro meses a produção alemã de armamento teria ficado totalmente paralisada? ${ }^{7}$. Revela, noutras passagens das suas memórias, como o mesmo tipo de situações se repetiu em relação a outros setores econômicos ${ }^{8}$ e observa que "o inimigo teria sem dúvida tido mais oportunidades de realizar a sua esperança de concluir a guerra durante o inverno de 1944-1945 se tivesse aniquilado a nossa indústria quimica"s. Speer apercebeu-se certamente de que não são nada convincentes as hipóteses que propõe para explicar um erro estratégico tão colossal e que se resumem, afinal, em admitir que os estados-maiores aliados estivessem mal informados ${ }^{10}$. $\mathrm{O}$ curioso é que, ao mesmo tempo que pretende isso no corpo do texto, em notas insinua algo de diferente, mostrando como o marechal Arthur Travers Harris, comandante-chefe dos bom-
6. BULLOCK, Alan. Hitler, A Study in Tyranny. Harmondsworth, Penguin Books, 1972, p. 699, $n^{9} 3$.

7. SPEER, Albert. Au Coeur du Troisième Reich. Paris Fayard (Le Livre de Poche), 1971, pp.380-2. A passagem citada é da página 382.

8. Idem, ibidem, pp.465-6, $468,530-1$ e 548 .

9. Idem, ibidem, p.747, n5. 10. Idem, ibidem, pp.382-3 e $721, n^{0} 22$. 
bardeiros britânicos, se opôs tenazmente ao próprio diretor das operações de bombardeamento, que pretendia a destruição sistemática das fábricas de rolamentos de esferas, objetivo que o marechal a todo o custo conseguiu evitar $^{\mathrm{n}}$, preferindo alvos civis. E era assim suspensa a devastação de centros industriais indispensáveis ao esforço de guerra para se lançarem terriveis ataques aéreos que chacinavam a população das grandes cidades ${ }^{12}$. Quando nem mesmo já Hitler se iludia sobre o destino final do nazismo, foi tomada em Berlim a decisão de destruir todas as infra-estruturas industriais da Alemanha, devendo um país em ruínas restar como perverso monumento àqueles que o haviam arruinado, num crepúsculo wagneriano dos infradeuses. Speer foi, então, um dos que se opuseram na prática às ordens do Führer e os governos aliados recompensaram-no em Nuremberg ao pouparem-lhe a vida, condenando-o a vinte anos de prisão. Não haveria de ser ele a deixar-se iludir quanto aos verdadeiros motivos da estratégia aliada mas, na delicada situação em que se encontrava ao publicar as memórias, apenas podia chamar a atenção para o problema, sem lhe denunciar as razões. Outros o fizeram.

Um eminente especialista francês escrevia, no começo de uma obra colossal: "É com efeito um fato de capital importância, prevalecendo sobre toda a economia alemã de hoje, que os bombardeamentos tivessem sido muito mais sensíveis sobre as cidades e os nós de comunicação do que sobre as forças produtivas. (...) a indústria pesada, base essencial da indústria de guerra, saía do conflito como a menos atingida de todas." Segundo os cálculoş em que esse economista se baseia, as minas $\mathrm{e}$ as indústrias do subsolo foram apenas destruídas em $10 \%$ e igual foi a percentagem na siderurgia; quanto à indústria química, apenas sofreu na proporção de $10 \%$ a $15 \%$ e a indústria mecânica de $15 \%$ a $20 \%$. Já a têxtil, foi atingida em $20 \%$, do mesmo modo

11. Idem, ibidem, pp.719$20, n^{\circ} \mathrm{s} 17$ e 20.

12. Idem, ibidem, pp.380, 383 e na 720 o final da $n^{-}$ 17.

13. PIETTRE, André. L'EConomie Allemande Contemporaine (Allemagne Occidentale), 1945-1952. Paris, Editions M.-Th. Génin, 1952, pp.65-7.

14. JACOBSSON, Erin E. $A$ Life for Sound Money, Per Jacobsson, His Biography. Oxford, Clarendon Press, 1979. prioridades na devastação: "Como explicar esta fúria desencadeada sobre as cidades, mais do que sobre as fábricas?" E resume a resposta, com aquele prodigioso cinismo que só os verdadeiros acadêmicos conseguem: "viu-se que era mais eficaz, para atingir uma indústria, visar ao pessoal, em vez de ao material (...) Os laços de interesses econômicos ou financeiros passando por cima das fronteiras (acordos econômicos ou investimentos de capital) foram, em alguns casos, um fator de proteção - de que as imensas instalações da IG Farben, poupadas no meio das ruinas, oferecem em Frankfurt um exemplo ostensivo. No mesmo sentido, pôde exercer efeitos o desejo de proteger certas empresas na vanguarda do progresso técnico: senão, como explicar, para citar apenas este exemplo, que a fábrica do Wiedia (aço especial, duro como o diamante, 'wie Diamant'), um dos motivos de orgulho da técnica alemã, tivesse sido a única intacta das fábricas Krupp em Essen, a duzentos metros de um campo de ruinas?"13.

Assim, a coesão supranacional das classes dominantes não se processou apenas no interior de cada um dos quadros político-ideológicos, mas entre eles também. Ao mesmo tempo que os trabalhadores se chacinavam uns aos outros, "visando ao pessoal", os capitalistas exprimiam uma solidariedade sem fronteiras, poupando "o material". A internacionalização das classes capitalistas, que se acelerou a partir de 1945 e atinge agora uma nova etapa, com a desagregação do bloco soviético, desenvolveu-se já, camufladamente, durante a própria Segunda Guerra Mundial. Nem se tratou de uma convergência apenas tácita, porque os beligerantes mantiveram instituições onde podiam coordenar a sua ação. Uma delas foi o Banco de Pagamentos Internacionais, estabelecido em Basiléia, na Suíça, e que na década de 1930 funcionava como um clube dos presidentes dos bancos centrais, onde podiam reunir-se e deliberar discretamente.

Per Jacobsson, que desde finais de 1956 até ao seu falecimento, em 1963, estaria à frente do Fundo Monetário Internacional, entrou, em 1931, para o Banco de Pagamentos Internacionais (BPI) como Conselheiro Econômico e Chefe do Departamento Econômico e Monetário. Conversador obsessivo e escrevinhador impenitente, manteve um detalhadíssimo diário, com que ocupou mais de duzentos cadernos, e que serviu de base à biografia factual que uma das suas filhas mais tarde se encarregou de escrever ${ }^{14}$. A abertura das hostilidades em agosto-setembro de 1939 não prejudicou "a harmonia em que conseguiam viver lado a lado, com toda a proximidade e sem dissensões, 
os funcionários do BPI, de tão variada origem internacional, com beligerantes de ambas as partes. Quando a guerra se desencadeou, todos os funcionários receberam instruções dos seus próprios bancos centrais para trabalhar amigavelmente em conjunto e assegurar assim a atividade do BPI"15. Nem era só uma oportunidade para a discussão de assuntos econômicos e financeiros que o Banco oferecia, pois Per Jacobsson se fazia habitualmente de intermediário entre representantes políticos e militares mais ou menos secretos ou chefes de espionagem mais ou menos públicos, de ambos os lados do conflito $^{16}$. Muitos outros funcionários de organismos estabelecidos em países neutros fizeram o mesmo e, além disso, os serviços de espionagem, contrariamente ao que tantos imaginam, que se servem para obter informações que o inimigo desejaria não revelar, destinam-se igualmente a passar ao inimigo propostas sem que nem o grande público, nem mesmo a maior parte dos dirigentes políticos, o saibam. Jacobsson foi nesse contexto um entre muitos, e certamente não dos mais importantes. $O$ que me parece decisivo na atividade do Banco de Pagamentos Internacionais durante a Segunda Guerra Mundial foi ter permitido a coordenação permanente das políticas financeiras dos bancos centrais de todos os países beligerantes. Assim como os bombardeiros do marechal do ar Harris não rompiam a continuidade do aparelho produtivo, também a manutenção do quadro de operações desse Banco possibilitou o regular funcionamento dos instrumentos monetários. A própria organização monetária, que os Aliados se preparavam para impor em todo o mundo, assim que tivessem definitivamente assegurada a vitória, foi previamente discutida com os banqueiros alemães. A conferência de Bretton Woods reuniu-se em julho de 1944. Pois em maio do ano anterior, Per Jacobsson encontra-se na Suíça com Emil Puhl, vice-governador do Banco central do Reich, que consigo trazia uma pequena delegação de banqueiros, incluindo, entre outros, Herman Abs, então presidente do Deutsche Bank. A reunião destinava-se a discutir os dois projetos que circulavam na preparação da futura conferência de Bretton Woods: o de Keynes, apresentado pelos britânicos, e aquele que acabaria por prevalecer, o plano norte-americano de Harry White. No final desse mesmo mês, Jacobsson visita Berlim, para de novo debater ambos os planos, durante três dias, com responsáveis do banco central e onde, em junho, fez uma palestra perante uma audiência composta de diretores de bancos co- merciais. É curioso considerar que as críticas então ouvidas ao documento elaborado por Keynes eram idênticas às formuladas pelos norte-americanos, e também os banqueiros alemães preferiram o plano White. $\mathrm{O}$ diário de Jacobsson revela-o, a 6 de maio de 1943, esforçando-se por persuadir os seus interlocutores germânicos de que a posição proeminente que iria ser conferida ao dólar não era exagerada, pois usando os norte-americanos $40 \%$ da produção mundial de matérias-primas industriais, a sua procura em dólares determinaria o nível mundial de preços. E, para suscitar a adesão dos banqueiros do Reich, procurava mostrar que o previsto quadro institucional oferecia um espaço de discussão que impediria a completa hegemonia dos Estados Unidos. A 26 de maio, já em Berlim, prevenia lucidamente que "será mais fácil aos alemães conseguirem influência num organismo técnico do que numa assembléia politica ${ }^{\prime 17}$. E assim, exatamente três meses após a rendição de Paulus em Stalingrad, quando mal o pêndulo da vitória começava a inclinar-se para os Aliados, já os banqueiros do Eixo participavam nas reuniões e debates em que se organizava a nova ordem monetária.

Não pode haver coesão mais sólida do que a forjada por cima de um conflito e é nesse quadro de internacionalização das classes capitalistas, reforçado precisamente no mesmo processo em que se lançavam umas contra as outras as populações trabalhadoras, que ainda hoje vivemos. Nos mecanismos das lutas sociais e da sua recuperação e assimilação, a mais decisiva vantagem de que se beneficiam os capitalistas é a sua internacionalização como classe, em flagrante contraste com o nacionalismo, que divide os trabalhadores. Enquanto tal situação durar, o atual modo de produção continuará numa fase ascendente, em plena expansão.

Não pretendi neste artigo encontrar qualquer explicação para o fenômeno, mas, apenas, antes de mais, chamar a atenção para ele. Em segundo lugar, procurei recordar que nem sempre a situação foi idêntica e que, durante vários anos, na Europa, as fronteiras que dividiam os capitalistas eram mais facilmente ultrapassadas pelo movimento dos trabalhadores. Finalmente, propus a hipótese de ter sido a crise desencadeada em 1929 e a sua resolução final com a Segunda Guerra Mundial a inverter o processo inaugurado em 1916-1917, conseguindo que as fronteiras nacionais separem os trabalhadores sem prejudicarem a coesão dos capitalistas. Talvez este artigo possa sugerir análises aprofundadas da questão.
15. Idem, ibidem, p.141.

16. Idem, ibidem, pp.152-7, 163-5 e 169-77.

17. Quanto à discussāo com os banqueiros alemães, preparatória de Bretton Woods, ver em JACOBS SON, Érin E. Op. cit., pp. 166 e 179-82. A passagem citada encontra-se na página 180. 